\section{IN BRIEF}

- Low-level, non-cutting lasers are commonly used in many areas of general medicine and veterinary practice.

- Their use in treating pathology is based on photobiostimulation, in which laser energy is absorbed by inter- and intra-cellular targets, resulting in a secondary stimulation of tissue healing mechanisms.

- In dentistry, a number of clinical conditions affecting the teeth and jaws may be amenable to low-level laser therapy.

- Photo-dynamic therapy, where a drug or chemical is introduced and activated by laser light, can be used in dentistry to treat bacterial infection in endodontics and periodontology.

- Additional uses of low-level laser light include caries detection and scanning techniques in orthodontics and restorative dentistry.

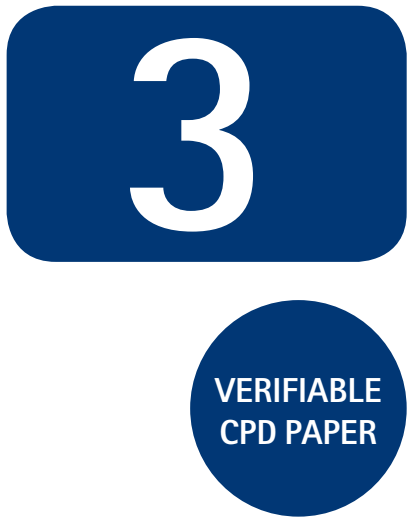

\title{
Low-level laser use in dentistry
}

\section{S. Parker ${ }^{1}$}

The use of laser light at power levels below that capable of direct tissue change (protein denaturation, water vaporisation and tissue ablation), has been advocated in diverse branches of medicine and veterinary practice, yet its acceptance in general dental practice remains low. However, the scope for using low-level laser light (LLLT) has emerged through many applications, either directly or indirectly tissue-related, in delivering primary dental care. The purpose of this article is to explain the mechanisms of action and to explore the uses of this group of lasers in general dental practice.

\begin{tabular}{l} 
LASERS IN DENTISTRY \\
\hline $\begin{array}{l}\text { 1. Introduction, history of lasers and } \\
\text { laser light production }\end{array}$ \\
\hline 2. Laser-tissue interaction \\
3. Low-level laser use in dentistry \\
4. Lasers and soft tissue: 'loose' soft \\
tissue surgery \\
\hline $\begin{array}{l}\text { 5. Lasers and soft tissue: 'fixed' soft } \\
\text { tissue surgery }\end{array}$ \\
\hline $\begin{array}{l}\text { 6. Lasers and soft tissue: periodontal } \\
\text { therapy }\end{array}$ \\
\hline $\begin{array}{l}\text { 7. Surgical laser use in implantology } \\
\text { and endodontics }\end{array}$ \\
\hline 8. Surgical lasers and hard dental \\
tissue \\
\hline 9. Laser regulation and safety in \\
general dental practice
\end{tabular}

${ }^{1}$ General Dental Practitioner, 30 East Parade, Harrogate, North Yorkshire, HG1 5LT

Correspondence to: Dr Steven Parker Email: thewholetooth@easynet.co.uk

\section{Refereed Pape}

๑ British Dental Journal 2007;

202: 131-138

DOI: $10.1038 /$ bdj.2007.75
THE USES OF LOW-LEVEL LASERS IN GENERAL DENTAL PRACTICE

A number of applications of low-level laser light have emerged, which utilise either the specific wavelength/chromophore relationship, or the inherent accuracy of a collimated beam. The most significant uses are listed as follows:

- Photobiostimulation

- Composite resin curing

- Caries detection

- Photo-activated disinfection (PAD)

- Laser scanning (restorative dentistry, orthodontics)

\section{PHOTOBIOSTIMULATION}

\section{Background}

The therapeutic effects of sunlight in treating a wide range of diseases has been recognised over many centuries, and are known collectively as heliotherapy. Systemic diseases, ranging from dementia and tuberculosis to skin diseases such as lupus vulgaris and acne, were commonly treated in the early part of the $20^{\text {th }}$ century by exposure to sun and other natural light. The development of treatments involving UV light, actinotherapy and photomedicine led to positive effects in helping patients suffering from rickets (vitamin D deficiency), together with claims of healing boils, carbuncles, neo-natal jaundice and for pain relief. ${ }^{1-3}$
Following the production of the first laser in 1960, itself a comparatively low-powered instrument, research into other lasers such as helium-neon (633 nm) followed. In Eastern Europe in the late 1960s, workers such as Mester, ${ }^{4}$ encouraged by laboratory experiments into regenerative healing effects in mice, treated patients with open wounds where conventional therapies had failed, reporting success rates of $85 \%$. During the 1970s and 1980s, the popularity of LLLT therapies grew, mainly in Europe and Asia, and with it, the development of diode lasers (GaAS $904 \mathrm{~nm}$, GaAlAs 780-890 $\mathrm{nm}$ and, latterly, InGaAlP 630-700 nm). All these lasers have deep penetrating potential in tissue and are portable, easy to use and relatively inexpensive. The use of these wavelengths centred around research that supported claims of benefits in treating musculo-skeletal, neuro-muscular, cytogenic and trauma-related conditions through biologic effects known as photobiostimulation. The underlying principle is that improvement in a condition is through stimulation of cellular and biochemically-mediated (essentially indirect) elements. ${ }^{5}$

\section{Application of LLLT in photobiostimulation}

The triage of dental treatment can be summarised as the control/eradication of disease, the control/relief of pain, and the restoration of form/function. The inter-relationship of 
Fig. 1 'The circle of suffering' inter-relationship between stimulus, response and pain
Fig. 2 Self-contained low level laser device (figure courtesy of $\mathrm{Dr}$ G. Ross, Toronto)

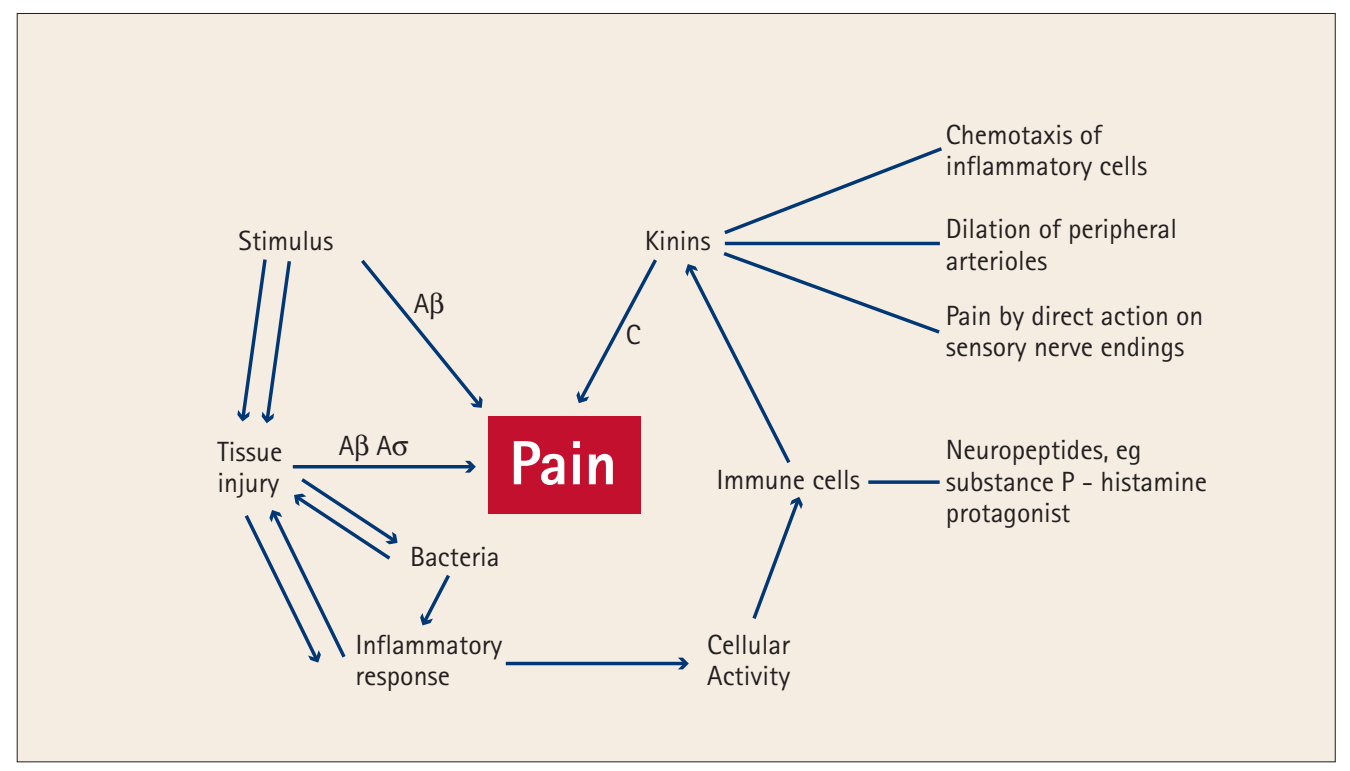

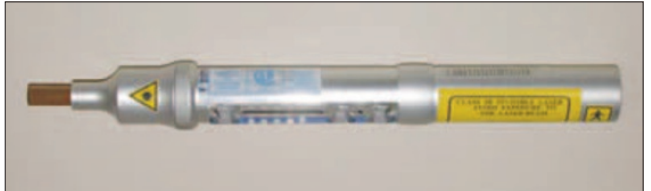

any stimulus with injury, cellular response and pain can be the product of the nature and potency of the stimulus and the ability of the tissue to respond (Fig. 1). Research on peri-apical lesions has shown that there is a correlation between the release of cellular and biochemical mediators and the nature of the injury, with acute and traumatic injuries resulting in greater reactive processes, compared to chronic pathogenesis. ${ }^{6}$

Low-level laser therapy (photobiostimulation) involves the use of visible red and near-infrared light with tissue in order to stimulate and improve healing, as well as reduce pain. The incident wavelength determines the effect - visible light is transmitted through the superficial cellular layers (eg the dermis, epidermis and the subcutaneous tissue). Light waves in the near-infrared ranges potentially penetrate several millimetres and these wavelengths are used to stimulate deep cellular function. Light energy is absorbed within living tissue by cellular photoreceptors, eg cytochromophores. The incident electromagnetic energy is converted by cellular mitochondria into ATP (adenosine tri-phosphate), a product of cytochrome c-oxidase activity and the Krebs cycle. ${ }^{7}$ Consequently, the stimulated increase in ATP production would suggest an increased cellular activity in eg fibroblasts, involved in tissue healing. ${ }^{8}$ In addition, the conversion of some of the incident energy into heat would suggest an increase in local micro-circulation through vasodilation.

The stimulatory effects of LLLT include the following: ${ }^{9-13}$

- Proliferation of macrophages

- Proliferation of lymphocytes
- Proliferation of fibroblasts

- Proliferation of endothelial cells

- Proliferation of keratinocytes

- Increased cell respiration/ATP synthesis

- Release of growth factors and other cytokines

- Transformation of fibroblasts into myofibroblasts

- Collagen synthesis.

In addition, there is evidence to support the analgesic effects of LLLT, through an enhanced synthesis of endorphins and bradykinins, decreased c-fibre activity and altered pain threshold. ${ }^{14,15}$ Other research suggests a therapeutic analgesic effect, through the release of serotonin and acetylcholine centrally, and histamine and prostaglandins peripherally, with the use of LLLT. ${ }^{16}$

\section{Laser units}

In comparison to surgical lasers, low-level laser units are much smaller, often self-contained, hand-held devices (Fig. 2), which are either battery-driven or charged via a pod in a bench-top master unit. There is no need for any integral cooling system and their power output levels often warrant no specific safety rules that apply to surgical laser units.

The dosimetry of low-level laser light is crucial to the infra-surgical effects of the wavelengths used. This is based on the Arndt Schultz law, ${ }^{17}$ summarised as 'small doses stimulate living systems, medium doses impede, and large doses destroy'. This is illustrated in a study carried out where hamster ovarian cells were exposed to varying low laser energy. ${ }^{18}$ The incident fluence, increasing through a range of infra-ablative values, gave rise to cellular effects as follows: a) $<60 \mathrm{~mJ} / \mathrm{cm}^{2}$ - zero bio-activation

b) $120-240 \mathrm{~mJ} / \mathrm{cm}^{2}$ - bio-stimulation

c) $240-300 \mathrm{~mJ} / \mathrm{cm}^{2}$ - zero bio-activation

d) $300-600 \mathrm{~mJ} / \mathrm{cm}^{2}$ - bio-inhibition (release of cellular singlet oxygen). 
The amount of laser energy delivered to a target tissue is termed fluence, or energy density and is measured in $\mathrm{J} / \mathrm{cm}^{2}$. The power of the laser light is the product of fluence and time, which for a free-running emission mode can result in peak power values of several thousand Watts, albeit for periods of micro-seconds. With surgical or cutting lasers, vaporisation of intra- and inter-cellular water occurs at fluence levels of 1,000 $\mathrm{J} / \mathrm{cm}^{2} \cdot{ }^{19}$ In clinical practice, low-level laser therapy, effective through stimulatory rather than ablative mechanisms, delivers fluence of $2-10 \mathrm{~J} / \mathrm{cm}^{2}$, depending on the target tissue ${ }^{20}$ as follows:

- Oral epithelium and gingival tissue - 2-3 $\mathrm{J} / \mathrm{cm}^{2}$

- Trans-osseous irradiation (target - periapical area) - 2-4 J/cm²

- Extra-oral muscle groups/TMJ - 6-10 $\mathrm{J} / \mathrm{cm}^{2}$.

Clinical applications in dental practice

It is perhaps best to consider the scope of application of LLLT in dentistry through the underlying cellular mechanism, rather than the descriptive clinical term. For example, tooth hypersensitivity may be viewed as an inflammatory condition and an extraction socket as post-trauma. In this way, the use of LLLT is to stimulate the inherent cellular and biochemical pathways associated with resolution and healing (Figs 3-5).

Reported effects in clinical dentistry include the following:

- Dentine hypersensitivity ${ }^{21}$

- Post-extraction socket/post-trauma sites ${ }^{22}$

- Viral infections: herpes labialis, herpes simplex ${ }^{23,24}$

- Neuropathy: trigeminal neuralgia, paraesthesia $^{25}$

- Apthous ulceration ${ }^{26}$

- TMJDS $^{25}$

- Post-oncology: mucositis, dermatitis, postsurgery healing. ${ }^{27}$

LLLT - the debate?

Despite the numbers of published studies $(2,500+)$, of which more than 100 are positive and double-blind, the acceptance of low-level lasers in primary dental therapy remains guarded. Approval and scepticism are curiously divided by geographical location, with greatest acceptance being expressed in Northern and Eastern Europe and Asia. Claims to the magnitude of the placebo effect in studies continue to fuel the lack of objective analysis. ${ }^{28}$ There is an increasing popularity being expressed in North America for LLLT use in dental practice and, whilst clinicians may choose to include such modalities in their practice, the need for wider-ranging evidence-based research must remain paramount, both for the credibility of this treatment and with respect to patients.

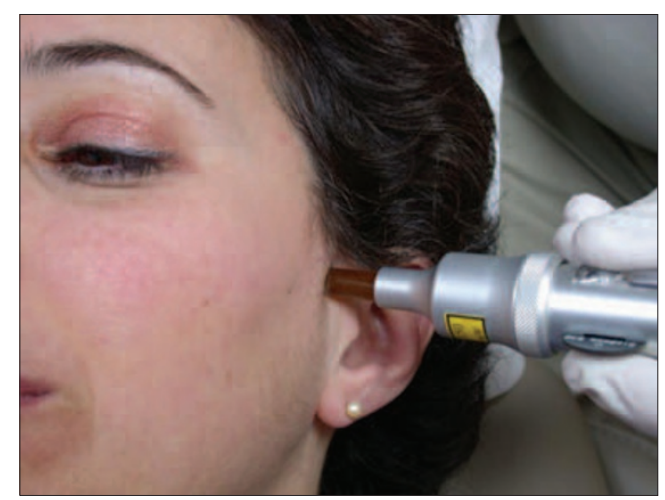

Fig. 3 TMJ stimulation (figure courtesy of Dr G. Ross, Toronto)

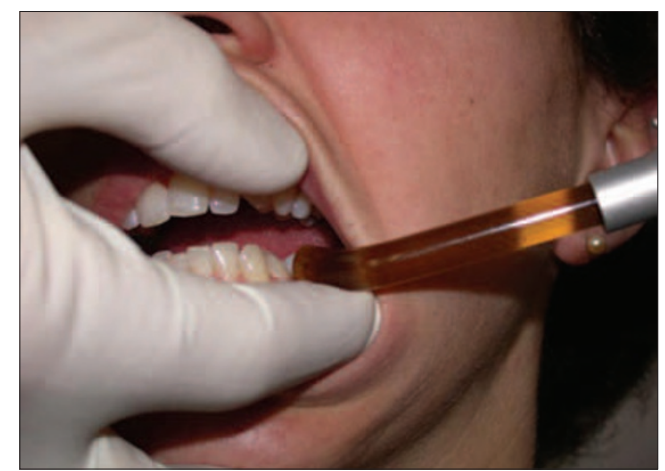

Fig. 4 Tooth hypersensitivity (figure courtesy of Dr G. Ross, Toronto)

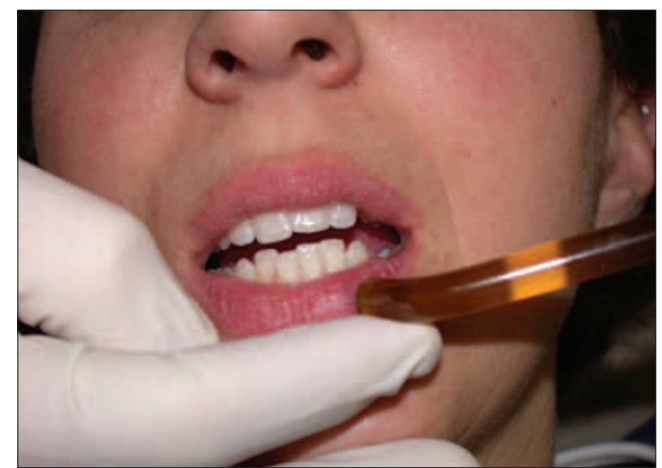

Fig. 5 Herpes labialis (figure courtesy of $\mathrm{Dr}$ G. Ross, Toronto)

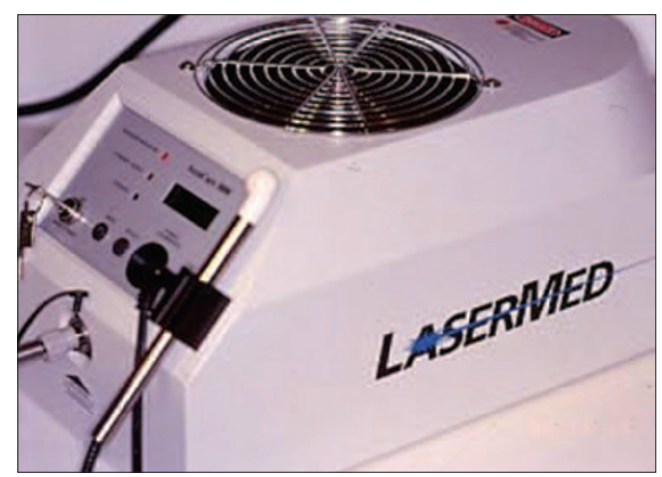

Fig. 6 Argon curing laser (LaserMed UK)

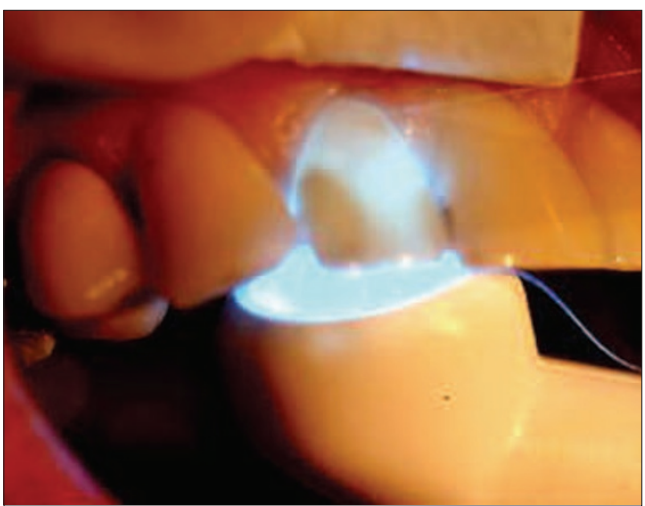

Fig. 7 Argon curing light 
Fig. 8 (left) DiagnoDENT (Kavo $\mathrm{GmbH)}$

Fig. 9 (right) Laser probe in use

Fig. 10 (left) Occlusal scan

Fig. 11 (right) Interstitial scan
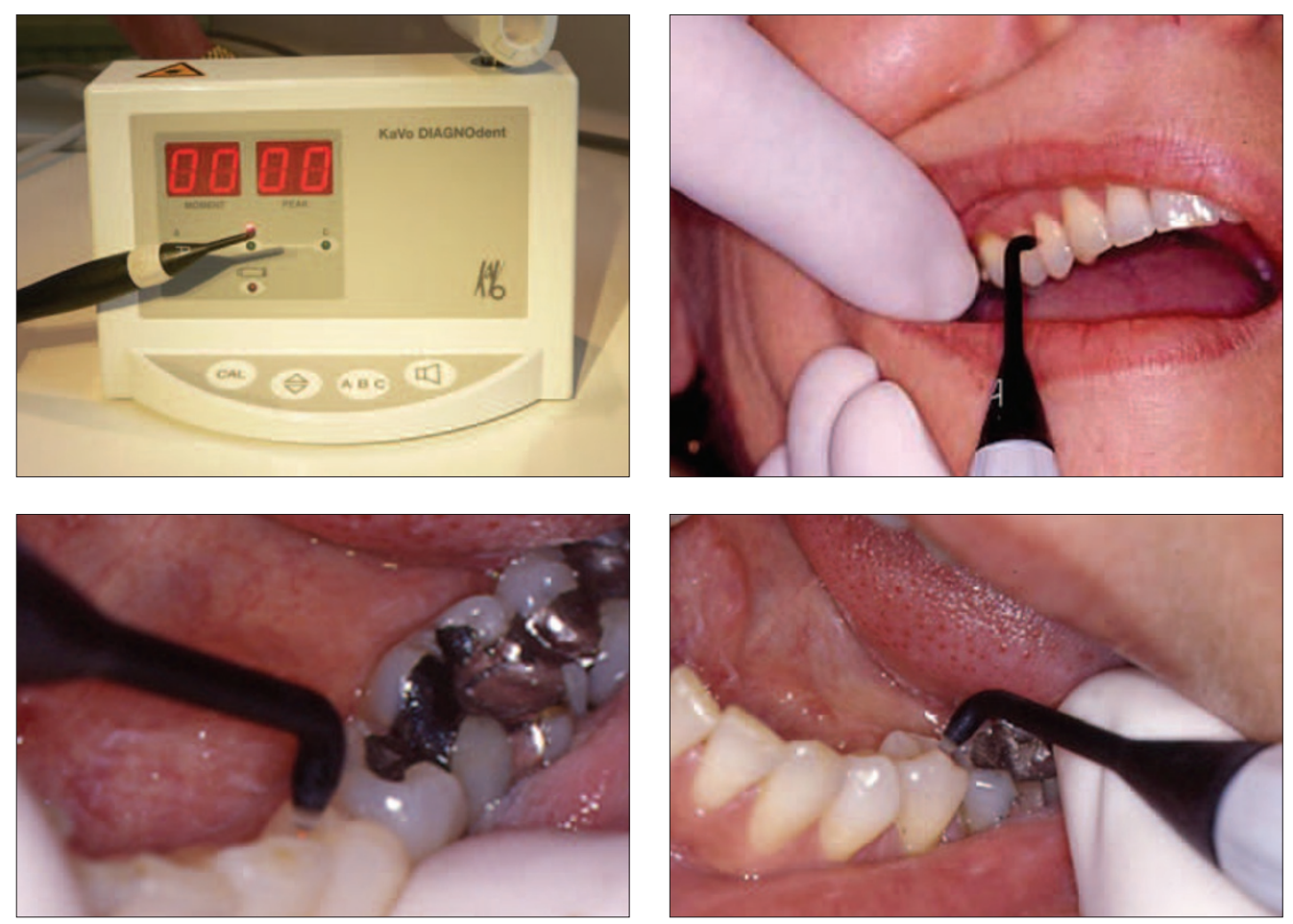

\section{COMPOSITE RESIN CURING}

One of the major emission wavelengths of argon lasers is the $488 \mathrm{~nm}$ 'blue'. This wavelength coincides with the absorption peak of camphorquinone, an accelerator used in composite resin restorative materials. The early work carried out on the effectiveness of a high density prime wavelength light source, suggested that the depth of curing and hardness of the set composite offered advantages over contemporary light curing systems. ${ }^{29-32}$ The intensity of the incident laser beam, using low power levels (150-300 mW) offered a light source that would enhance desired restorative properties without excessive pulpal temperature rise.

Unfortunately, the duality of emission wavelengths of the argon active medium required selective filtering of the longer, 514 nm 'green' (soft tissue ablative) wavelength, together with the limitation of the hardware required to restrict emission light energy. Consequently, argon laser curing units were expensive and rendered suitable only for composite curing and some laser whitening uses (Figs 6 and 7). In addition, the simultaneous development of more powerful curing systems (eg plasma-arc curing lights), offered similar results without the cost and peripheral safety requirements of the laser unit.

\section{CARIES DETECTION}

Although the use of fluorescence had been suggested for caries detection already more than a century ago, the current optical caries detection techniques emerged with the introduction of laser technology into the dental field. In the 1980s, a clinically applicable visual detection ${ }^{33,34}$ method focussing on the natural green fluorescence of tooth tissue was developed. The technique used a 488 $n m$ excitation wavelength from an argon-ion laser to discriminate bright green fluorescing healthy tooth tissue from poorly fluorescing caries lesions. The technique was developed further in the early 1990s, into what is now known as quantitative light-induced fluorescence (QLF), ${ }^{35,36}$ using the digitisation of fluorescence images to quantify the observed green fluorescence loss as an indirect measure of mineral loss.

Around that time, in veterinary dental research and human dental research, a red fluorescence method emerged. The red fluorescence, excited either using long UV (350$410 \mathrm{~nm}$ ) or red (550-670 $\mathrm{nm}$ ) wavelengths, was observed in advanced caries as well as plaque and calculus on teeth. ${ }^{37,38}$ Opposite to the green fluorescence loss observed in caries, a substantial red fluorescence occurs between 650 and $800 \mathrm{~nm}$ in caries lesions that is much brighter than that of sound enamel or dentine. ${ }^{39-41}$

The first commercially available unit using a red laser was manufactured by Kavo (Kavo $\mathrm{GmbH}$ ) in 1998, with an emission wavelength of $655 \mathrm{~nm}$ (Fig. 8). The effectiveness of this system is deemed to be best incorporated as an adjunct to other diagnostic methods (tactile, visual, radiographic), to limit the possibility of 'false positive' results, which is borne out in recent studies. ${ }^{42}$ Nonetheless, the unit, which offers a reproducible analogue scoring of site examination, allows a degree of objective assay of those suspect areas of caries that are subject to on-going review as to treatment. Primarily, the use of this modality has been to detect occlusal or flat surface defects, although interstitial caries can be recorded (Figs 9-11). The presence of existing 


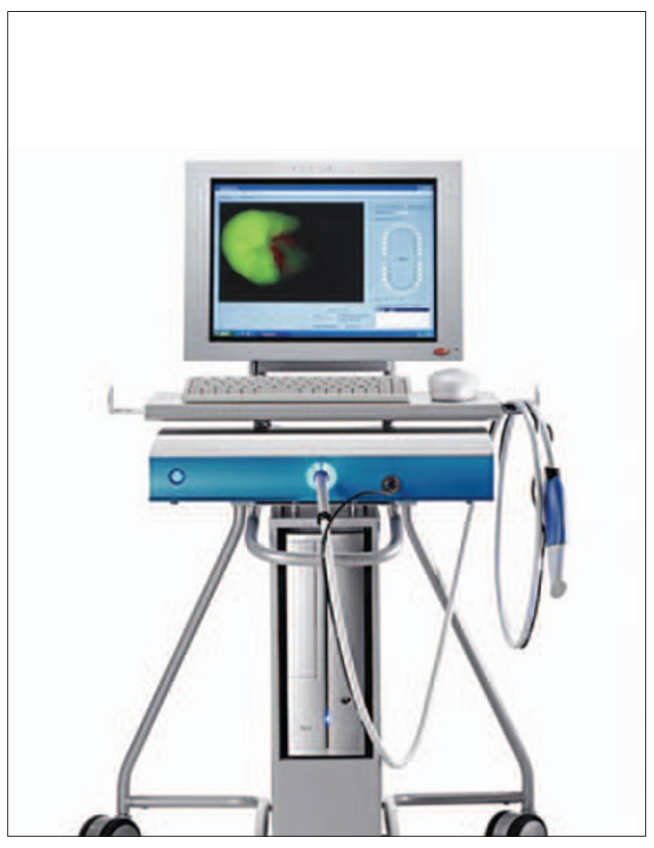

restorations, amalgam, gold, porcelain and composite, would only allow marginal caries to be detected.

New-emerging techniques in laser-assisted caries detection

Quantitative light-induced fluorescence. This is a highly sensitive method for determining short-term changes in lesions in the mouth. ${ }^{43}$ The control unit consists of an illumination device and imaging electronics. The argonion laser was replaced in 1995 by a xenonbased arc-lamp and the light from this lamp is filtered by a blue-transmitting filter. A liquid light-guide transports the blue light to the teeth in the mouth and a dental mirror provides uniform illumination of the area to be recorded. The excitation wavelength around $405 \mathrm{~nm}$ produced by the system allows visualisation and quantification of both the dental tissues' intrinsic green fluorescence as well as the red fluorescence from bacterial origin as observed in calculus, plaque and (advanced) caries. $^{44,45}$ The green fluorescence loss observed from demineralised enamel as well as natural caries lesions is strongly correlated with mineral loss. ${ }^{46-48}$ The red fluorescence offers insight into oral hygiene levels, allows visualisation of leaking margins of sealants and restorations ${ }^{44}$ and is furthermore suggested for use during caries excavation. ${ }^{49}$

Dental calculus produces the most pronounced fluorescent intensity, carious regions produce a slightly weaker fluorescent intensity. Photo-images of this technique are given in Figures 12-16 (source www.inspektor.nl).

PS-OCT - polarisation-sensitive optical coherence tomography. Preliminary studies using OCT have proven successful at imaging hard and soft tissue in the oral cavity. Using polarisation-sensitive OCT (PS-OCT), a numerical analysis of the optical properties of the surface and subsurface enamel can be

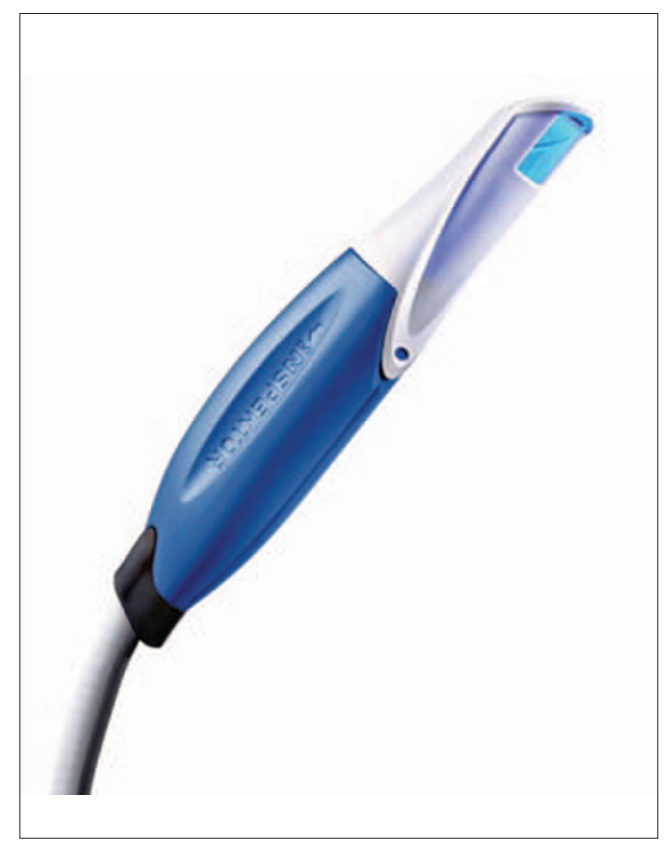

Fig. 12 (left) Quantitative lightinduced fluorescence. QLF unit and computer hardware (courtesy of Inspektor Dental Care BV, Amsterdam, NL)

Fig. 13 (right) QLF hand-piece (courtesy of Inspektor Dental Care BV, Amsterdam, NL)

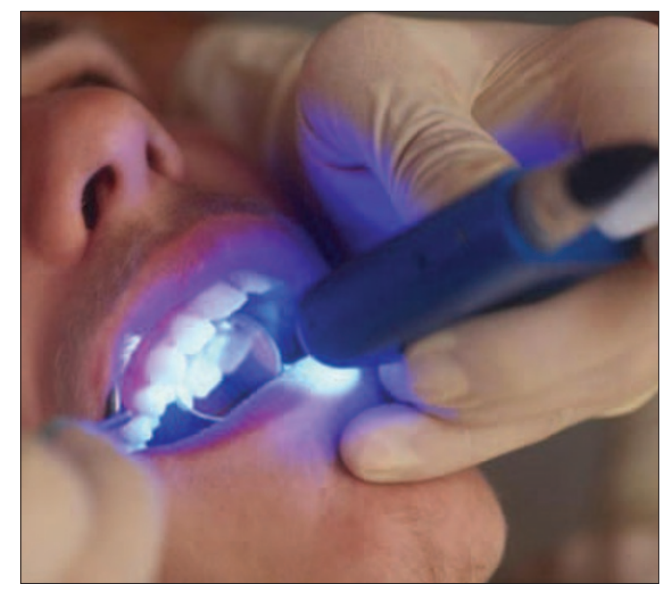

Fig. 14 QLF unit in use in the mouth (courtesy of Inspektor Dental Care BV, Amsterdam, NL)
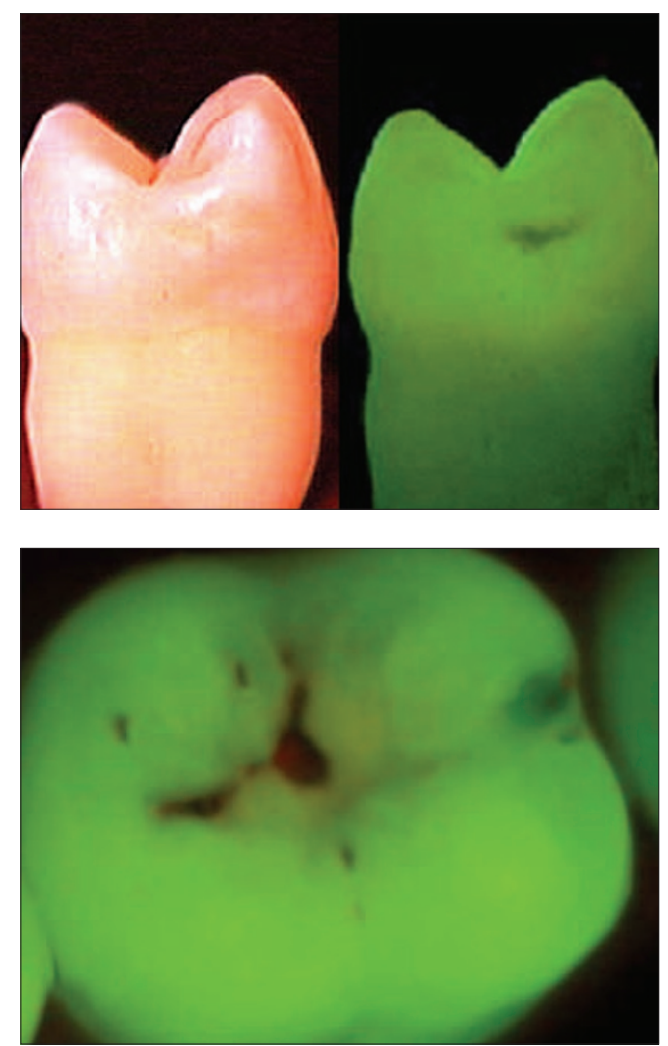

Fig. 15 Premolar before and after exposure, showing decalcified area (courtesy of Inspektor Dental Care BV, Amsterdam, NL)

Fig. 16 Occlusal caries (courtesy of Inspektor Dental Care BV, Amsterdam, NL) 


\section{PRACTICE}

Fig. 17 (left) Photo-activated disinfection of prepared cavity, upper second molar (courtesy of T. Von

Fig. 18 (right) Photo-activated disinfection of prepared cavity, Von Samson and Denfotex UK) Samson and Denfotex UK) upper first molar (courtesy of T.
Fig. 19 (left) Laser probe in tooth cavity (courtesy of T. Von Samson and Denfotex UK)

Fig. 20 (right) Cavity decontamination (courtesy of T. Von Samson and Denfotex UK)

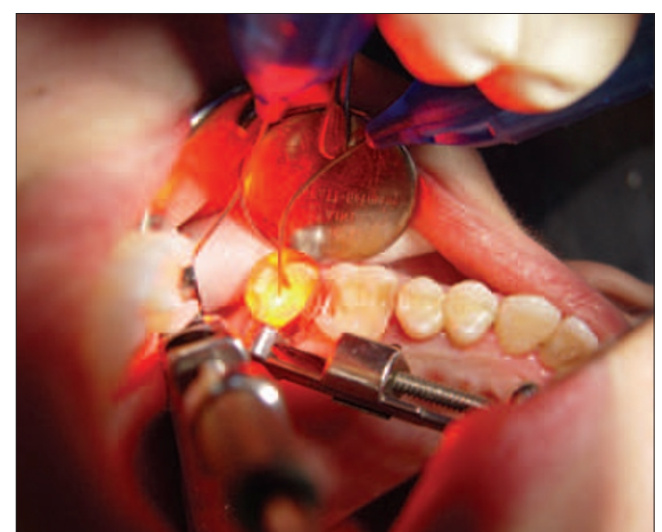

obtained. At research levels, using a nearinfrared beam ( $\lambda 1,310 \mathrm{~nm})$, caries detection is possible at both surface level and under composite restorations and sealants. ${ }^{50,51}$

Recent developments have seen the emergence of other spectroscopic analysis devices which are undergoing development, eg a blue InGaN laser diode operating at $405 \mathrm{~nm} .{ }^{52}$

\section{PHOTO-ACTIVATED DISINFECTION (PAD)}

This is a development over and above the conventional use of chemicals to achieve bacterial decontamination in restorative dentistry. As opposed to chemicals that are spontaneously interactive with cellular structures, PAD employs a photo-activated liquid, a solution of tolonium chloride (a pharmaceutical grade of the vital stain toluidene blue 0). Exposure of this chemical to low-level visible red light $(635 \mathrm{~nm})$ releases singlet oxygen that ruptures bacterial cell walls ${ }^{53}$ (Figs 17 and 18).

During the early 1990 s at the Eastman Dental Institute, London, Professors M. Wilson and G. Pearson first proved PAD

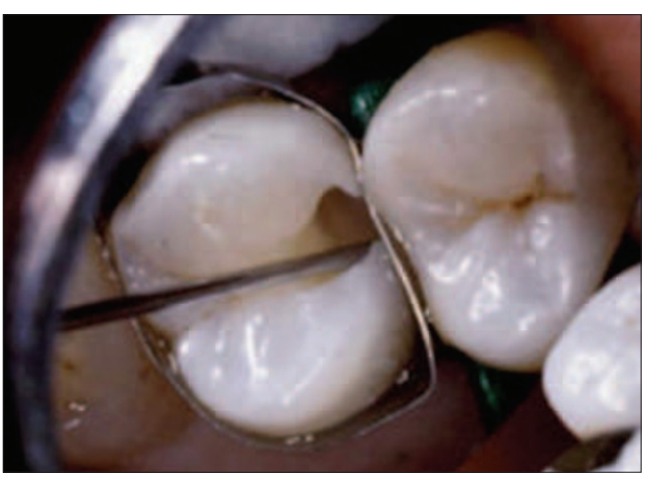

Fig. 21 (left) Completed restoration (courtesy of T. Von Samson and Denfotex UK)

Fig. 22 (right) Hand-piece and fibre. The fibre diameter equates to ISO \# 40 (reproduced with permission, Denfotex UK)

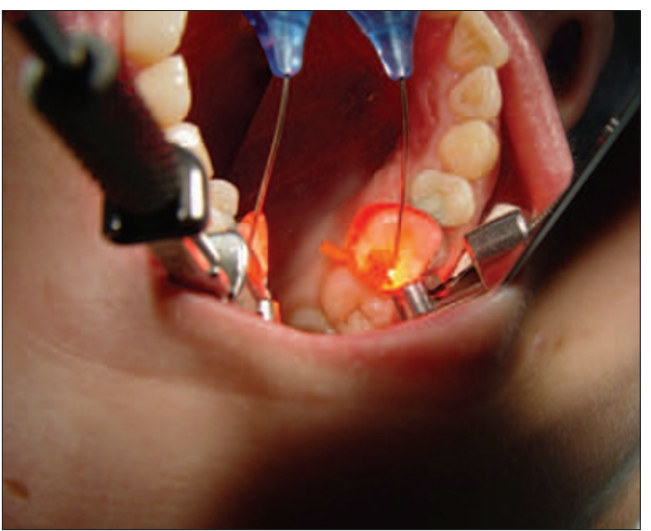

killed Streptococcus mutans ${ }^{54}$ in significant numbers, and reasoned that PAD could kill all bacteria involved in oral infections in caries, root canals, and periodontics, ${ }^{55}$ thereby eliminating the most common oral infections. Research was undertaken to determine the susceptibility to photo-activated disinfection (PAD) of Streptococcus mutans when the organism was present in a collagen matrix $^{56}$ - an environment similar to that which would exist within a carious tooth. This research has led to the production of a commercial unit for use in dental surgery (Figs 19-22).

Recent in vitro and in vivo studies ${ }^{57,58}$ into the use of PAD in endodontics have demonstrated the effectiveness of this therapy against a number of anaerobic bacterial strains associated with endodontic infections (Fusobacterium nucleatum, Peptostreptococcus micros, Prevotella intermedia and Streptococcus intermedius). In addition, PAD has been shown to be effective against Enterococcus faecalis. ${ }^{59}$
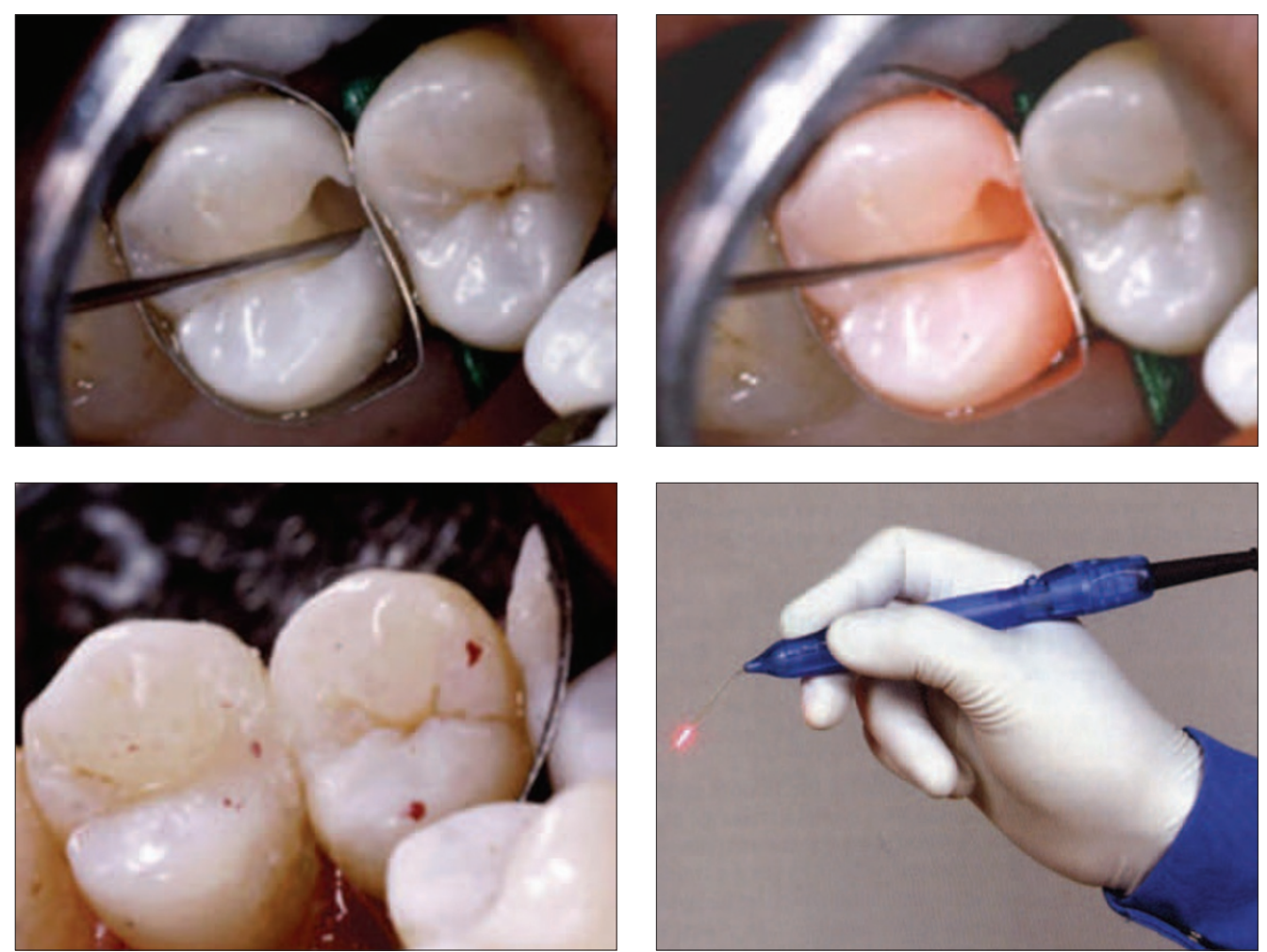


\section{LASER SCANNING (ORTHODONTICS, \\ RESTORATIVE DENTISTRY)}

The development of laser-based measuring devices (eg the confocal micrometer), utilising beam-splitting of a low-energy laser and optical detector, has enabled accurate replication of the morphology of dental and oral structures and materials used in restorative dentistry.

The earliest use of laser scanning was in the field of orthodontics and facial development, to provide 3D imaging and recording of pre- and post-treatment of deformities. ${ }^{60-62}$ Scanned data was linked to computer software using CAD (computer-assisted design).

This concept has been expanded during the last decade, to enable the scanning of restorative cavities prior to the production of cast or milled indirect restorations, ${ }^{63}$ and the recording of oral and facial swellings. ${ }^{64}$

An additional associated use of laser light in oral medicine is through Raman spectroscopy. A Raman spectrum represents the scattering of incident laser light by molecular or crystal vibrations. Such vibration is quite sensitive to the molecular composition of samples being investigated, and areas of research include the in vitro and in vivo study of disease processes such as cancer, atherosclerosis and bone disease. With regard to the latter, Raman spectroscopic analysis in vivo of mineral and matrix changes has been shown to be useful in mapping early changes in bone tissue. ${ }^{65}$

Permission granted by Dr Gerry Ross, Toronto, Canada to reproduce clinical photographs, Denfotex UK in showing photo-activated disinfection and Inspektor Dental Care BV, The Netherlands for QLF information, is gratefully acknowledged.

1. Scott B. Clinical uses of ultraviolet radiation. GK edition. Baltimore: Stillwell, 1983

2. Cuncliffe W J. Diseases of the skin. Br Med J 1973 4: 667-669.

3. Ennever J F. Phototherapy for neonatal jaundice. Photochem Photobiol 1988; 47: 871-876.

4. Mester E, Spiry T, Szende B et al. Effect of laser rays on wound healing. Am J Surg 1971: 122: 532-535.

5. Wolbarsht M L (ed). Clinical aspects of laser research. pp 116. New York: Plenum Press, 1977.

6. Torabinejad M, Mindroiu T, Bakland L. Detection of kinins in human periapical lesions. J Dent Res 1989; 68: 201.

7. Passarella S. Increase of proton electrochemical potential and ATP synthesis in rat liver mitochondria irradiated in vitro by helium-neon laser. FEBS Lett 1984 : 175: 95-99.

8. Karu T. Photobiological fundamentals of low powered laser therapy. IEEE J Quantum Electron 1987; 23: 1703-1717.

9. Dube A, Bansal H, Gupta P K. Modulation of macrophage structure and function by low level He-Ne laser irradiation. Photochem Photobiol Sci 2003; 2: 851-855.

10. Stadler I, Evans R, Kolb B et al. In vitro effects of low-level laser irradiation at $660 \mathrm{~nm}$ on peripheral blood lymphocytes. Lasers Surg Med 2000; 27: 255-261.

11. Kreisler M, Christoffers A B, Willershausen B, d'Hoedt B. Effect of low-level GaAlAs laser irradiation on the proliferation rate of human periodontal ligament fibroblasts: an in vitro study. J Clin Periodontol 2003; 30: 353-358.

12. Kovacs I B, Mester E, Gorog P. Stimulation of wound healing with laser beam in the rat. Experientia 1974; 30: $1275-1276$.

13. Enwemeka C S, Parker J C, Dowdy D S, Harkness E E, Sanford $L E$, Woodruff $L D$. The efficacy of low-power lasers in tissue repair and pain control: a meta-analysis study. Photomed Laser Surg 2004; 22: 323-329.

14. Honmura A. Therapeutic effect of GaAlAs diode laser irradiation on experimentally induced inflammation in rats. Lasers Surg Med 1992; 12: 441-449.

15. Laakso E L, Cramond T, Richardson C, Galligan J P. Plasma ACTH and $\beta$-endorphin levels in response to low level laser therapy for myofascial trigger points. Laser Ther 1994; 3: 133-142.

16. Montesinos M. Experimental effects of low power laser in encephalon and endorphin synthesis. J Eur Med Laser Assoc 1988; 1: 2-7.

17. Schultz H. Ueber hefegifte. Pflugers Archiv fur die gesamte Physiologie des Menschen und der Tierre 1888; 42: $517-541$.

18. Al-Watban. Effect of HeNe laser and Polygen on $\mathrm{CHO}$ cells. J Clin Laser Surg Med 2000; 18: 145-150.

19. Takata A N, Zaneveld L, Richter W. Laser-induced thermal damage in skin. Aerospace Med Rep 1977; Rep. SAM-TR77-38

20. Bjordal J M, Couppe, $C$, Ljunggren A. Low level laser therapy for tendinopathies; evidence of a dose-related pattern. Phys Ther Reviews 2001; 6: 91-100.

21. Kimura $Y$, Wilder-Smith $P$, Yonaga K, Matsumoto K. Treatment of dentine hypersensitivity by laser; a review. J Clin Periodontol 2000: 27: 715-721.

22. Taube S, Piironen J, Ylipaavalniemi P. Helium-neon laser therapy in the prevention of post-operative swelling and pain after wisdom tooth extraction. Proc Finn Dent Soc 1990; 86: 23-27.

23. Vélez-González M, Urrea-Arbaláes $A$, Serra-Baldrich $E_{\text {, }}$ Pavesi M, Camarasa J M, Trelles M A. Treatment of relapse in herpes simplex on labia and facial areas and of primary herpes simplex on genital areas and "area pudenda" with low power HeNe laser or acyclovir administered orally. Proc SPIE 1995; 2630: 43-50.

24. Schindl $A$, Neuman R. Low intensity laser therapy is an effective treatment for recurrent herpes simplex infection: results from a randomised double-blind placebo controlled study. J Invest Dermatol 1999; 113: 221-223.

25. Pinheiro A L, Cavalcanti E T, Pinheiro T I, Alves M J, Manzi C T. Low-level laser therapy in the management of disorders of the maxillofacial region. J Clin Laser Med Surg 1997; 15: 181-183

26. Howell R M, Cohen D M, Powell G L, Green J G. The use of low energy laser therapy to treat aphthous ulcers. Ann Dent 1988; 47: 16-18.

27. Wong S F, Wilder-Smith P. Pilot study of laser effects on oral mucositis in patients receiving chemotherapy. Cancer J 2002; 8: 247-254.

28. Wilder-Smith P. The soft laser; therapeutic tool or popular placebo? Oral Surg Oral Med Oral Pathol 1988; 66: 654-658

29. Kelsey W P, Blankenau R J, Powell G L, Barkmeier W W, Stormberg E F. Power and time requirements for use of the argon laser to polymerize composite resins. J Clin Laser Med Surg 1992; 10: 273-278.

30. Talbot T Q, Blankenau R J, Zobitz M E, Weaver A L, Lohse C $M$, Rebellato J. Effect of argon laser irradiation on shear bond strength of orthodontic brackets: an in vitro study. Am J Orthod Dentofac Orthop 2000; 118: 274-279.

31. Powell G L, Blankenau R J. Effects of argon laser curing on dentin shear bond strengths. J Clin Laser Med Surg 1996: 14: 111-113.

32. Blankenau R J, Kelsey W P, Powell G L, Shearer G O, Barkmeier W W, Cavel W T. Degree of composite resin polymerization with visible light and argon laser. Am J Dent 1991; 4: 40-42.

33. Bjelkhagen $H$, Sundström F. A clinically applicable laser luminescence method for the early detection of dental caries. IEEE J Quantum Electron 1981; 17: 266-270

34. Bjelkhagen $H$, Sundström $F$, Angmar-Månsson $B$, Ryden $\mathrm{H}$. Early detection of enamel caries by the luminescence excited by visible laser light. Swed Dent J 1982; 6: 1-7.

35. Hafström-Björkman U, Sundström F, de Josselin de Jong $\mathrm{E}$, Oliveby $\mathrm{A}$, Angmar-Månsson $\mathrm{B}$. Comparison of laser fluorescence and longitudinal microradiography for quantitative assessment of in vitro enamel caries. Caries Res 1992; 26: 241-247.

36. de Josselin de Jong $E$, Sundström $F$, Westerling $H_{\text {, }}$ Tranaeus S, ten Bosch J J, Angmar-Månsson B. A new method for in vivo quantification of changes in initial enamel caries with laser fluorescence. Caries Res 1995; 29: 2-7.

37. König K, Hibst R, Meyer H, Flemming G, Schneckenburger $\mathrm{H}$. Laser-induced autofluorescence of carious regions of human teeth and caries-involved bacteria. Proc SPIE 1993; 2080: $170-180$ 
38. Dolowy W C, Brandes M L, Gouterman M, Parker J D, Lind $J$. Fluorescence of dental calculus from cats, dogs, and humans and of bacteria cultured from dental calculus. J Vet Dent 1995; 12: 105-109.

39. Hibst R, Gall R. Development of a diode laser-based fluorescence detector. Caries Res 1998; 32: 294.

40. Hibst R, Paulus R. Caries detection by red excited fluorescence: investigations on fluorophores. Caries Res 1999; 33: 295.

41. Lussi A, Megert B, Longbottom C, Reich E, Francescut P. Clinical performance of a laser fluorescence device for detection of occlusal caries lesions. Eur J Oral Sci 2001; 109: 14-19.

42. Bader J D, Shugars D A. A systematic review of the performance of a laser fluorescence device for detecting caries. J Am Dent Assoc 2004; 135: 1413-1426.

43. Stookey G K. Optical methods - quantitative light fluorescence. J Dent Res 2004; 83 (Suppl): C84-C88.

44. Heinrich-Weltzien R, Kühnisch J, van der Veen $M$, de Josselin de Jong E, Stosser L. Quantitative light-induced fluorescence (QLF) - a potential method for the dental practitioner. Quintessence Int 2003; 34: 181-188.

45. van der Veen $M H_{1}$, Buchalla $W$, de Josselin de Jong $\mathrm{E}$. QLF ${ }^{\mathrm{TM}}$ technologies: recent advances. In Stookey G K (ed) Early detection of dental caries III: proceedings of the 6 th Indiana conference. pp 291-304. Indianapolis: Indiana University School of Dentistry, 2003.

46. Hafström-Björkman U, Sundström $F$, de Josselin de Jong $E$, Oliveby $A$, Angmar-Månsson B. Comparison of laser fluorescence and longitudinal microradiography for quantitative assessment of in vitro enamel caries. Caries Res 1992; 26: 241-247.

47. Emami $Z, A l-K h a t e e b S$, de Josselin de Jong $E$, Sundström F, Trollsås K, Angmar-Månsson B. Mineral loss in incipient caries lesions quantified with laser fluorescence and longitudinal microradiography. A methodologic study. Acta Odontol Scand 1996; 54: 8-13.

48. Ando M, van Der Veen M H, Schemehorn B R, Stookey G K. Comparative study to quantify demineralized enamel in deciduous and permanent teeth using laser- and lightinduced fluorescence techniques. Caries Res 2001; 35: 464-470.

49. Lennon A M, Buchalla W, Switalski L, Stookey G K. Residual caries detection using visible fluorescence. Caries Res 2002; 36: 315-319.

50. Fried D, Xie J, Shafi S, Featherstone J D, Breunig T M, Le C. Imaging caries lesions and lesion progression with polarization sensitive optical coherence tomography. J Biomed Opt 2002; 7: 618-627.

51. Jones R S, Staninec M, Fried D. Imaging artificial caries under composite sealants and restorations. J Biomed Opt 2004; 9: 1297-1304.
52. Ribeiro A, Rousseau C, Girkin J et al. A preliminary investigation of a spectroscopic technique for the diagnosis of natural caries lesions. J Dent 2005; 33: 73-78.

53. Soukos N S, Wilson M, Burns T, Speight P M. The photodynamic effects of toluidine blue on human oral keratinocytes and fibroblasts and Streptococcus sanguis evaluated in vitro. Lasers Surg Med 1996; 18: 253-259.

54. Burns T, Wilson M, Pearson G J. Sensitisation of cariogenic bacteria to killing by light from a helium/neon laser. Med Microbiol 1993; 38: 401-405.

55. Wilson M, Dobson J, Harvey W. Sensitisation of oral bacteria to killing by low-power laser radiation. Current Microbiol 1992; 25: 77-81.

56. Williams J A, Pearson G J, Colles M J, Wilson M. The photo-activated antibacterial action of toluidine blue 0 in a collagen matrix and in carious dentine. Caries Res 2004; 38: $530-536$.

57. Williams J A, Pearson G J, John Colles M. Antibacterial action of photoactivated disinfection $\{P A D\}$ used on endodontic bacteria in planktonic suspension and in artificial and human root canals. J Dent 2006; 34: 363-371.

58. Bonsor S J, Nichol R, Reid T M, Pearson G J. Microbiological evaluation of photo-activated disinfection in endodontics (an in vivo study). Br Dent J 2006; 200: 337-341.

59. Lee M T, Bird PS, Walsh L J. Photo-activated disinfection of root canals: a new role for lasers in endodontics. Austr Endod J 2004: 30: 93-98.

60. McCance A M, Moss J P, Wright W R, Linney A D, James D R. A three-dimensional soft tissue analysis of 16 skeletal Class III patients following bimaxillary surgery. Br J Oral Maxillofac Surg 1992; 30: 221-232.

61. McCance A M, Moss J P, Fright W R, James D R, Linney A $D$. A three dimensional analysis of soft and hard tissue changes following bimaxillary orthognathic surgery in skeletal III patients. Br J Oral Maxillofac Surg 1992; 30: 305-312.

62. Commer $\mathrm{P}$, Bourauel $\mathrm{C}$, Maier K Jager A. Construction and testing of a computer-based intraoral laser scanner for determining tooth positions. Med Eng Phys 2000; 22: 625-635.

63. Denissen H W, van der Zel J M, van Waas M A. Measurement of the margins of partial-coverage tooth preparations for CAD/CAM. Int J Prosthodont 1999; 12: 395-400.

64. Harrison J A, Nixon M A, Fright W R, Snape L. Use of hand-held laser scanning in the assessment of facial swelling: a preliminary study. Br J Oral Maxillofac Surg 2004; 42: 8-17.

65. Tarnowski C , Ignelzi M A Jr, Wang W, Taboas J M, Goldstein S A, Morris M D. Earliest mineral and matrix changes in force-induced musculoskeletal disease as revealed by Raman microspectroscopic imaging. J Bone Miner Res 2004; 19: 64-71. 